\title{
Prof. Peixoto Cabral
}

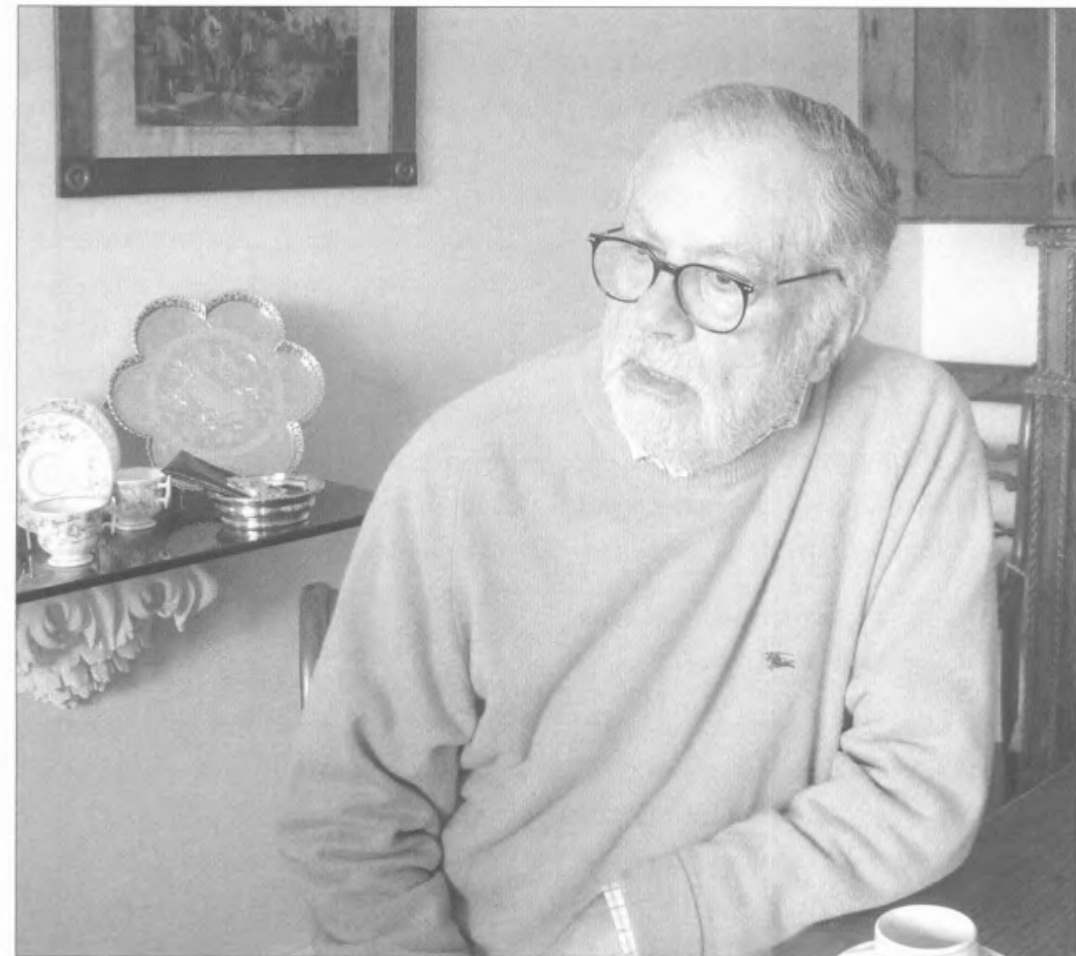

O Prof. Peixoto Cabral, sendo um Engenheiro Químico de formação, desde o início da sua carreira que se dedicou à Radioquímica. Tendo trabalhado sob a supervisão do Prof. A. Herculano de Carvalho no Centro de Estudos de Radioquímica (IST) da Comissão de Estudos de Energia Nuclear (CEEN), qual foi a influência deste ilustre professor, que tantas vezes aparece como um centro irradiante da Química em Lisboa, na sua decisão de optar pelo nuclear?

A influência foi enorme. Foi o Prof. Herculano de Carvalho que, pouco depois de eu ter concluído a licenciatura em 1952, me convidou a entrar (como bolseiro) para o Grupo de Química que ele estava a organizar tendo em vista o desenvolvimento da área de Radioquímica no seu Departamento e a preparação de gente para a futura Junta de Energia Nuclear (JEN). É interessante salientar que já nessa altura se praticavam métodos radioquímicos no seu laboratório designadamente um método para determinar a concentração de radão em águas, sobretudo nas águas minerais. Era o tempo em que a radioactividade nestas águas era considerada uma característica altamente benéfica. De facto, lembro-me bem que nos rótulos de certas garrafas se punha em destaque essa sua caracterísitica, a água mais radioactiva do mundo... (risos)... Não se fazia uso, porém, de nuclidos radioactivos artificiais. Talvez por isso ele me tivesse manifestado, logo de início, o seu gosto por ver incluída no seu laboratório a aplicação desses radionuclidos. Devo confessar que a ideia me despertou um enorme interesse.

Foi nesse caso o Prof. Herculano de Carvalho que o estimulou a sair para o estrangeiro? Como é que obteve a bolsa?

Ele estava preocupado em dar preparação a todos os bolseiros e sabendo que ela não podia ser realizada em Portugal, começou a procurar diversos lugares onde pudesse fazer-se. Mas não foi só ele. Foram também outros dirigentes da Comissão de Estudos, como o Prof. Leite Pinto, que era o presidente, e o Prof. Carrington da Costa, da Universidade do Porto. Surgiu uma primeira oportunidade na Isotope School, do Centro Nuclear inglês de Harwell, próximo de Oxford, que era o maior centro de investigação nuclear do Reino Unido, e o Prof. Herculano de Carvalho achou que não se deveria perdê-la e inscreveu-me.

\section{E a sua bolsa quem a financiou?}

Foi o Instituto para a Alta Cultura.

Em 1953 com 25 anos apenas, já era diplomado pela Isotope School, em Harwell. E três anos depois diplomado pela Reactor School, no mesmo local. Quer contar-nos um pouco da sua experiência desse período?

Como disse há pouco, frequentei em 1953 o curso da Isotope School no seguimento da ideia do Prof. Herculano de Carvalho que seria útil aprender as técnicas de manipulação de espécies radioactivas, com toda a segurança ... 
isso era uma questão que ele considerava absolutamente essencial ... e também alguns métodos de aplicação dessas espécies em química, sobretudo em química analítica. Esse curso foi muito útil para mim, pois ajudou-me enormemente na etapa seguinte da minha formação na Alemanha. Sabiamos que o curso da Isotope School era um curso relativamente curto e na altura em que fui frequentá-lo já se pensava numa preparação mais longa. Já se sabia da possibilidade de ir estagiar com o Prof. Paneth, um célebre radioquímico que nâo trabalhava na Alemanha mas sim no Reino Unido, e eu mostrei-me interessado nessa possibilidade. Aconteceu. porém, que o Prof. Paneth, que era um judeu austríaco e fugira dos nazis para Inglaterra, tinha sido entretanto convidado para ir dirigir o Max Planck Institut für Chemie, em Mainz. Assim eu, que era para ir trabalhar com o Prof. Paneth para Inglaterra, como já estava comprometido com ele, acabei por ir parar ao Max Planck Institut ...

\section{E já sabia alemão?}

Não, não. Tive dificuldades grandes com o alemão. Mas como no Max Planck todos falavam inglês, não tive propriamente dificuldades no Instituto quanto à língua.

\section{De certa maneira esta estada no Max Planck foi marcante para a sua carrei-} ra

Sim, é verdade, foi no Max Planck Institut que eu me defrontei pela primeira vez com o fascínio da investigação. Nunca tinha presenciado essa actividade verdadeiramente, nem convivido com gente que a fizesse de modo sistemático, que a exercesse, nem tão pouco com as dificuldades da investigação. Foi aí que realmente comecei a sentir essas dificuldades. Foi nesse Instituto também que eu reconheci a minha fraquíssima preparação, em particular no que se refere ao trabalho experimental, e que tomei consciência da enorme pobreza dos nossos laboratórios de quimica em instrumentos e oficinas. Foi ainda aí que eu me apercebi que o caminho da realização duma tese de doutoramento seria porventura o melhor para preparar investigadores. Repare que nessa altura ainda não se faziam doutoramentos no Instituto Superior Técnico, nem ninguém pensava nisso. É pois natural que o Prof. Herculano de Carvalho tivesse escolhido outro caminho... Apesar disso, o estágio no Max Planck Institut foi muitíssimo proveitoso, não só por me ter dado numerosos conhecimentos e alguma prática laboratorial, como ainda por me ter aberto os olhos para novas perspectivas. Julgo que esta abertura que se deu em mim e nos meus colegas, que foram levados a seguir caminhos análogos e passaram por experiências semelhantes, terá contribuido significativamente para que a vaga de bolseiros enviados pelo Prof. Herculano de Carvalho para o estrangeiro, depois da nossa, onde já estava incluído por exemplo o Fraústo, tivesse enveredado pela via do doutoramento. Foi aí que de facto as coisas começaram. Mas entre nós, bolseiros antigos, era unânime a opinião que esse era o caminho (do doutoramento).

Lembra-se de alguns nomes dos seus colegas bolseiros dessa época?

Sim. sim. Marques Videira que foi para Sheffield, Carlos Lloyd Braga que foi para Cambridge, Amélia Rézio, Carlos Pulido e Ricardo Cabrita que foram para Uppsala. Era um grupo de cerca de meia dúzia de pessoas que foram para o estrangeiro mas, como disse, não para fazerem doutoramentos. A política era fundamentalmente a realização de estágios. E portanto as nossas estadias não passaram para além de dois anos, à volta disso, com as dificuldades inerentes a essa dita actividade. De facto, a maior parte dos professores que nos recebiam não entendiam bem porque nos mandavam daquela maneira. E foi precisamente ao regressar que trouxemos essa mensagem, que aquilo na nossa opinião não estava a ser conduzido da melhor forma. E. que haveria que corrigir. Admito também que o próprio Prof. Herculano de Carvalho, e outros, em contacto permanente com os seus colegas no estrangeiro, e até com os nossos supervisores, se teriam também apercebido dessa insuficiência, e de facto acabaram por corrigi-la. A tal "segunda ge- ração" já caminhou para o doutoramento.

O Prof. Peixoto Cabral, acabou por fazer o seu Doutoramento em Ciências Básicas de Engenharia, pela Universidade Técnica de Lisboa, em 1968. Tinha então 39 anos. Atendendo à penúria dos laboratórios da Universidade nessa época, como conseguiu realizar o seu trabalho experimental de doutoramento?

Fiz o trabalho experimental na Secção de Radioquímica do Departamento de Química do LFEN (Laboratório de Física e Engenharia Nucleares) em Sacavém que foi criado na segunda metade dos anos 50 pela JEN e inaugurado em 1961. Pouca gente sabe que esse Departamento foi projectado por uma equipa do Centro de Estudos do IST, liderada pelo Eng. Fernando Marques Videira, da qual eu fazia parte. Ele foi o primeiro dessa equipa a entrar na JEN e foi desde logo incumbido de ir dirigir o Departamento. Eu ainda me mantive no IST, mas efectuando já muito trabalho para o projecto da Secçāo de Radioquímica. Faço notar, porém, que o LFEN foi inaugurado com os laboratórios praticamente vazios e que o seu apetrechamento foi um processo lento e cheio de dificuldades, inclusive de ordem financeira. Apesar disso, a JEN era na altura a entidade com maiores meios para a investigação, o que nos permitiu instalar no LEFN laboratórios que, não sendo magnificos, eram os mais bem apetrechados da área de Lisboa. No que respeita à Radioquímica, eram mesmo os únicos onde se podia trabalhar com toda a segurança. Só no fim de 1962 é que conseguimos obter as condições mínimas para começar a fazer algum trabalho experimental. Foi também por essa data que começámos a recrutar pessoal recém-licenciado e a preparálo. Sabia, contudo, que só poderíamos fazê-lo parcialmente e que se tornava necessário promover a sua saida para universidades estrangeiras dado que, nas nossas, pouca investigação se realizava e muito menos na área da Radioquímica. Procurámos, por isso, estabelecer contactos com professores de algumas daquelas universidades ou rea- 
tar antigas relações, como por exemplo com o Prof. Maddock, da Universidade de Cambridge, que conhecíamos desde os tempos do Centro de Estudos do IST. Procurámos por outro lado obter a ajuda de certos investigadores portugueses com alguma formação nesta área, como o Prof. Pinto Coelho da Universidade de Coimbra. Mas foi sobretudo o Prof. Maddock que nos prestou um auxilio precioso, na medida em que orientou três teses de doutoramento, uma das quais a minha, e intercedeu junto de colegas seus da Universidade de Cambridge para se encarregarem doutros doutorandos. É interessante notar que em quase dez anos conseguimos doutorar na Secção de Radioquimica cinco pessoas. É claro que não foi nada fácil para mim realizar o trabalho experimental para a tese e simultaneamente zelar pela gestão da secção nesta primeira fase de desenvolvimento. Não admira por isso que só em 1967 o tivesse concluído e só em 1968 tivesse defendido a tese. Talvez valha a pena referir que foi o segundo doutoramento em Química no IST. O primeiro foi o do Fraústo. Foi um doutoramento tardio, mas foi dos primeiros... (risos).

Em 1960, aos 32 anos, é chefe de trabalhos no Laboratório de Física e Engenharia Nucleares, onde criou e liderou um grupo de Investigação em Radioquímica. 1968 encontra-o já investigador-chefe e 1978 como investigadorcoordenador do Departamento de Química do LNETI. Finalmente em 1992 é nomeado Director do IJF. Ou seja, desde muito novo ocupou postos de chefia com pesadas responsabilidades em termos de gestão financeira e de recursos humanos, de que forma isso afectou a sua carreira em investigação científica?

Bom, prejudicou num certo sentido porque, como sabem, todas essas tarefas exigem tempo, por vezes até muito tempo. Perde-se muito tempo com burocracias...

e o trabalho de gestão de recursos humanos, não é só burocracia...

Sim, exactamente. De qualquer modo também é estimulante. Passei para coordenador do Departamento na altura em que o Marques Videira foi convidado a criar uma nova Direcção Geral na JEN destinada a pôr em prática um programa de instalaçâo no nosso pais de reactores nucleares para produzir energia. Julgo que terá sido útil para o Departamento a minha passagem, devido à persistência em defender uma boa preparação básica das pessoas e à convicção, que há pouco referi, de que a melhor maneira de a levar a cabo era aquela que passaria pela realização dum doutoramento. $\mathrm{O}$ que nem sempre foi bem atendido pelo Dr. Carlos Cacho, Director do LFEN, nem por um ou outro assistente, obrigando-me a uma luta continua. Consegui fomentar no Departamento um ambiente estimulante e isso terá contribuido grandemente para que se tivessem formado nele grupos de investigação com uma dimensão razoável que permitiu o seu desenvolvimento e continuidade. Grupos que ganharam crédito e o respeito dos nossos colegas de Laboratório e da Universidade. Criouse escola, creio eu.

Os lugares de topo oferecem a vantagem de poder por em prática projectos muito ambiciosos...

\section{Exactamente..}

...mas num laboratório de estado, ou numa instituição digamos estatal, é necessário obter financiamentos e para isso é preciso saber comunicar com o poder político, ou seja, de formular recomendações que são aceites. Qual foi a sua experiência nesse domínio?

É certo que a obtenção de meios financeiros foi uma tarefa muito difícil. Foi necessário insistir, insistir muitas vezes, procurar persuadir as entidades superiores, digamos assim, no sentido de encontrarem esses meios, e de os persuadir de que efectivamente os motivos eram nobres, eram importantes... Mas também procurámos obter esses meios no estrangeiro. Inicialmente era muito complicado porque a IAEA (Agência Internacional de Energia Atómica), por motivos de natureza política, tinha uma certa dificuldade em aceitar a ideia de auxiliar Portugal...
...Porque era uma ditadura...

...Havia o problema político relacionado com a questão colonial, que julgo terá criado dificuldades sérias desse ponto de vista mas, mesmo assim, conseguimos obter algum auxilio da IAEA. Depois, com a vinda da revolução, as coisas felizmente alteraram-se e então, a partir daí, a IAEA passou a ser muito mais aberta e conseguiram-se auxilios financeiros muito mais substanciais.

E quem eram as entidades superiores que davam financiamento...

Na parte relativa ao LFEN era a Junta de Energia Nuclear que principalmente financiava...

Que dependia directamente da Presidência do Conselho de Ministros...portanto estava muito perto do poder político...

Sim, exactamente. Nem havia outra alternativa, não havia nenhuma Fundação que permitisse obter financiamentos... já havia a Fundação Gulbenkian. Mas, de qualquer modo, seria muito difícil a Fundação Gulbenkian financiar projectos relacionados com a Energia Nuclear.

Em 1982, publica na revista Arqueologia um artigo intitulado "Instalação dum laboratório de radiocarbono: um projecto adiado". A unidade de datação pelo ${ }^{14} \mathrm{C}$, cuja instalação é da sua responsabilidade, entra em funcionamento em 1986. Ou seja houve alguns percalços pelo caminho, quer contar-nos um pouco sobre o assunto?

Desde 1975 que procurei enveredar por caminhos de investigação em áreas de intersecção das Ciências com as Humanidades sobretudo com a Arqueologia. Sabia que uma das dificuldades que os arqueólogos portugueses tinham era no dominio da datação. Necessitavam de datas para alguns materiais que iam recolhendo e não era fácil obtê-las em laboratórios estrangeiros. Sabia além disso que seriamos capazes de instalar no instituto, que nessa altura já nẫo pertencia à JEN mas sim ao LNETI, uma unidade de datação pelo radiocarbono baseada no processo convencional, isto é, na medição da actividade do ${ }^{14} \mathrm{C}$ presente nas amostras. E consegui persua- 
dir o presidente do LNETI, que era o Prof. Veiga Simāo, a meter um bolseiro para esse fim, o Monge Soares, e a financiar a sua preparação em Cambridge. Aconteceu, porém, que mais tarde, devido a uma má informação do Dr. Carvalho Rodrigues, do Departamento de Fisica, que não percebeu porque é que eu propunha a instalação duma unidade convencional quando já existia um novo processo, o de espectrometria de massa de iões acelerados, com maior produtividade e que permitia datar amostras muito mais pequenas, a iniciativa foi travada. É claro que, quando fiz a proposta, estávamos perfeitamente conscientes desta realidade, mas tínhamos consciência também de que a entrada do acelerador na datação pelo ${ }^{14} \mathrm{C}$ não tornara obsoleto o processo convencional. Basta dizer que a maior parte das amostras dos arqueólogos têm tamanho suficiente para serem datadas por este processo. Sabíamos ainda que o custo de primeira instalação do processo convencional era muitíssimo menor que o do processo do acelerador e que estava ao alcance do LNETI, ao contrário do que se passava com o outro. Enfim, acabámos por reconhecer que não avançariamos se nāo tivéssemos o auxílio dos arqueólogos e dai o ter escrito o citado artigo. Valeu-nos o director do Museu Nacional de Arqueologia que conseguiu obter um subsidio e com isso levar o Veiga Simão a aprovar a proposta. Mas levou tempo. Devo acrescentar que esta unidade de datação foi de grande utilidade para os arqueólogos e ainda continua a ser....

Quem era na altura o director do Museu Nacional de Arqueologia? E donde veio o financiamento?

Era o Dr. Francisco Alves e o financiamento veio do Instituto Português do Património Cultural.

O Prof. Peixoto Cabral foi não só pioneiro na introdução das técnicas de datação em Portugal como também antecipou o interesse da interface entre a Química e as Ciências Humanas. Como surgiu o seu interesse por esta interface?
Sempre me interessei por algumas áreas das Ciências Humanas. Por outro lado, aconteceu que ao consultar a bibliografia científica, no decurso da minha actividade como químico, me fui dando conta de aplicações importantes de alguns métodos praticados no LFEN em estudos de tais áreas, o que ajudou a consolidar esse interesse. Um dia, em 1974, encontrei acidentalmente no elevador da minha casa o meu vizinho Dr. Montalvão Machado, que na altura desempenhava um alto cargo na Associação dos Arqueólogos Portugueses, a quem contei um pouco do que lera. Aconselhou-me então a expor o assunto na referida Associação, o que fiz numa conferência marcada para o efeito. A esta conferência assistiram alguns arqueólogos que ficaram por sua vez interessados, o que facilitou futuras relaçôes. Mas não foi apenas o meu interesse por essas áreas que contribuiu para a viragem do meu percurso de investigador. Foi também a decisão política do governo português de se abandonar a via nuclear para a produção de energia. Esta decisão trouxe como consequência a extinção da JEN e, naturalmente, alteraçōes significativas na orientação das actividades dos órgãos que a constituiam, em particular do LFEN que transitou para o LNETI criado em 1977, cujo nome mudou mais tarde para INETI. Chegaram mesmo por essa altura a transmitir superiormente que teríamos de mudar de vida, de orientá-la noutras direcçōes embora não nos tivessem definido com clareza quais os novos objectivos a atingir. Foi então que eu, no que se refere ao meu grupo, tomei a iniciativa de contactar directamente alguns arqueólogos informandoos da nossa disponibilidade em colaborar com eles em projectos de investigaçāo onde se reconhecessem vantagens em aplicar métodos que tínhamos desenvolvido, particularmente o de análise por activação com neutrões. E surgiram alguns projectos. Foi deste modo que demos início a uma série de trabalhos sobre cerâmicas arqueológicas, actividade que ainda hoje se mantém. Mas não foi só isso que fizemos. Outras coisas foram realizadas, como a análise não-destrutiva de arte- factos metálicos pré-históricos, a análise não-destrutiva de moedas antigas para apoiar estudos de história monetária, a datação pelo radiocarbono de que falei há pouco, etc.. Se quiserem saber mais pormenorizadamente $\mathrm{o}$ que efectuámos nos dez primeiros anos de arqueometria no LNETI leiam o artigo que sobre isso publiquei em 1989 na revista Arqueologia... Quanto aos outros dois grupos do Departamento, o de Química dos Elementos $f$, liderado pelo Pires de Matos, e o de Química do Estado sólido, liderado pelo Manuel de Almeida, a situação criada pelo abandono da via nuclear levantou talvez maiores dificuldades. Havia pressōes para que se acabasse com a investigação fundamental que neles estava em curso e se substituísse por outra mais virada para a indústria. Isso criou algumas perturbações e tornou-nos a vida complicada. Todavia continuei, na minha qualidade de director do Departamento, a defender com veemência junto do Prof. Veiga Simão que tal mudança, a concretizar-se, deveria ser feita com muita precaução $e$ tendo sempre em conta que aqueles grupos estavam ainda em formação e não deveriam ser prejudicados. Foi uma luta dificil que felizmente terminou com vantagens para ambos os grupos, na medida em que conseguiram produzir um excelente trabalho, doutorar muita gente, e ficar bem mais fortificados. Mas remou-se sempre contra a maré, pois não era essa de facto a vontade do Veiga Simão. Verdade se diga, no entanto, que ele sempre reconheceu o grande mérito das suas investigações e, talvez por isso, acabou por aceitar a situação. 0 único grupo do Departamento que continuava a fazer aplicações era o meu. Simplesmente também era criticado, porque muitas delas eram mais para o lado das humanidades do que para o lado da indústria... (risos).

No entanto uma parte significativa da sua actividade científica acaba por ser na área das humanidades.

Sim, a partir do fim dos anos 70 a minha maior contribuição foi dada em áreas de intersecção com as Humanidades. Mas não deixei de continuar interessado nalgumas áreas da Química e da sua inter- 
secçāo com outras disciplinas das Ciências, em particular da Geoquímica. Com efeito, o grupo que eu liderei realizou, para além de trabalhos de Arqueometria, muitos outros trabalhos sobretudo de química analítica e geoquímica ou, dito doutro modo, de ciências do ambiente. Mais, colaborámos também umas vezes por outras nalguns trabaIhos do grupo do Pires de Matos e do grupo do Manuel de Almeida.

O seu percurso científico passou pela Direcção do Instituto José de Figueiredo (actualmente Instituto Português de Conservação e Restauro), de Maio de 1992 a Dezembro de 1993. É do domínio público que se demitiu. À primeira vista tratava-se do Homem certo no lugar certo. $O$ que é que não funcionou?

Bom, o problema do Instituto José de Figueiredo é um problema complicado...(risos).

\section{...bicudo...(risos)...}

....eu fui para o Instituto José de Figueiredo a convite da Dra. Simoneta Afonso, que era a directora do IPM (Instituto Português de Museus) do qual dependia o IJF. A princípio devo confessar que hesitei, mas acabei por me deixar aliciar e aceitei. Quando aceitei, lembro-me perfeitamente de ter referido à Dr. Simoneta que uma coisa absolutamente essencial era preparar gente de maneira conveniente, a tal passagem por um doutoramento...

\section{...na sequência de todo o seu percur-} so...

...exactamente. Falei-Ihe nisso e ela pareceu-me estar de acordo com a proposta. Julgo que ela própria estava interessada em promover a entrada de gente nova no IJF, com ideias novas, seguindo caminhos novos. E que terá tido dificuldades para obter meios financeiros que permitissem a concretização desse propósito. Os museus, que a Dra. Simoneta acima de tudo procurava modernizar, levavam-Ihe uma enorme fatia do orçamento. E da fatia magra que sobrava para o IJF uma boa parte destinava-se às despesas de conservação e restauro de objectos dos museus, so- bretudo dos seleccionados para exposições que ela se empenhava em promover em ritmo acelerado. Já tive dificuldade em introduzir o primeiro doutorado no IJF, que era o António João Cruz. E, apesar de ele ter o doutoramento e se mostrar bastante apto, nâo consegui que ele entrasse para o quadro do Instituto. Trabalhou sempre como contratado, a quem se pagava com recibo verde. Também me recordo do caso da Carmo Serrano, agora no IPCR, que me tinha aparecido num dado instante para fazer um estágio, para a qual procurei obter uma bolsa e que nunca consegui. Ela acabou por realizar o estágio sem retribuição. Isso leva a pensar que a Dra. Simoneta teria tido dificuldades em obter financiamentos... Eu gostaria de ter reformado o IJF introduzindo uma nova mentalidade, novas pessoas com uma formação sólida, particularmente na área da Química. É certo que existia lá gente de boa qualidade, sobretudo excelentes artífices. Havia pessoas competentes para a realização de certas tarefas. Mas a maior parte delas tinha uma preparaçāo científica básica muito fraca. E ela é muito necessária... O meu primeiro ano no IJF foi estimulante, na medida em que me permitiu enfrentar uma série de questōes interessantes no âmbito da Conservação e Restauro. Permitiu-me, além disso, iniciar o projecto de estudo dos Painéis do Nuno Gonçalves e realizar o estudo da pintura de Silva Porto. Vivi entusiasmado, na tentativa de criar realmente condições novas no Instituto, de fomentar a investigação quer na área da Conservação quer na área da História da Arte... Mas nos últimos meses, quando comecei realmente a verificar que nada daquilo que eu gostaria de introduzir tinha possibilidade de avançar...

.. É curioso que a Dra. Simoneta me deu sempre a sensação de que concordava comigo, e eu acreditei durante ainda um bom pedaço de tempo que ela teria possibilidade de obter essas condições; e ainda estou crente que ela terá feito esforços nesse sentido, que era esse de facto o seu desejo, mas que ela própria também foi vencida por uma série de dificuldades de diferentes naturezas. Ela é realmente uma pessoa inte- ligente, dinâmica e voluntariosa. Dei-me muito bem com ela. Não tive, pode dizer-se, nenhuma dificuldade na relação. Se ela tivesse encontrado as tais condiçōes, eu teria continuado a trabaIhar no IJF. Mas não foi capaz, e quando eu me compenetrei que efectivamente não era mesmo possivel realizar reformas significativas no Instituto, achei que o melhor era sair... Confesso que houve também coisas, relacionadas com o comportamento de algumas pessoas do Instituto, que contribuíram para acelerar a saída. Por vezes, é difícil lidar com algumas dessas pessoas, em particular porque têm uma mentalidade de tal forma diferente da nossa, eu digo da nossa formada no âmbito das Ciências, que é muito difícil estabelecer ou manter o diálogo com elas. Lembro-me, por exemplo, que a dada altura do projecto sobre a pintura do Nuno Gonçalves se criou inesperadamente entre mim e a minha adjunta, com quem tinha tido até ai uma boa relação, um estado de tensão por causa da recolha de amostras para a análise da camada pictórica. Estávamos a estudar o painel do São Vicente na cruz em aspa. Esta tábua apresenta-se muito deteriorada por xilófagos e eu achava, perante uma tāo grande abundância de estragos, que a recolha de uma dúzia de finíssimas e pequeníssimas amostras não aumentaria significativamente os danos, mas em contrapartida traria com certeza benefícios para o conhecimento da técnica do Nuno Gonçalves. Ela retorquia, porém dogmaticamente, que era uma barbaridade fazer isso. Acabei por decidir que as recolhessem e ela foi fazer queixa à Dra. Simoneta, o que achei muito feio. Como não tenho feitio para entrar em guerra com as pessoas, quando me fazem coisas deste teor aquilo que me apetece é ir-me embora.

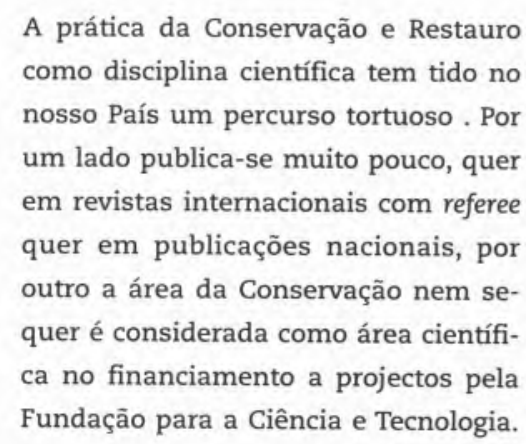


A Conservação e Restauro pode vir a ter algum futuro em Portugal?

Eu penso que a Conservação e o Restauro podem e devem ter importância, porque há realmente um patrimónic que, em comparação com o de Itália, não se pode dizer que seja muito grande...(risos)...mas que é significativo. É o nosso património, que nós devemos preservar. Eu acho, portanto, que a Conservação e o Restauro são actividades muito importantes, que deveriam ser realizadas da melhor maneira. Considero, como disse há pouco, que a formação de base da maior parte das pessoas com quem convivi era relativamente modesta. Apercebi-me que certas coisas que entravam no IJF para restauro criavam dificuldades e problemas enormes. A pintura de cavalete seria talvez a área mais fácil para o Instituto, onde havia uma maior experiência. Lembrome, por exemplo, de um objecto lindíssimo, provavelmente medieval, com trabalho em esmalte, em que este último estava a deteriorar-se, a cair, e ninguém sabia fazer nada por ele... e era absolutamente indispensável que se fizesse. Havia áreas onde não se sabia mesmo nada. Era óbvio que se precisava de formar pessoas, em diversos domínios, para que se pudesse atender devidamente a tudo $o$ que na realidade havia para fazer. Considero pois que a Conservação e o Restauro sāo actividades importantes, que têm futuro, e que mereciam, de facto, um grande cuidado no que se refere à formaçầo de pessoal competente. Não há nenhuma tradição no nosso País no que se refere às licenciaturas, e sobretudo aos doutoramentos em Conservação. Quem são as pessoas doutoradas no nosso país em matéria de Conservação e Restauro?

\section{...A Ana Isabel Seruya ${ }^{*}$...}

... a Ana Isabel Seruya é uma física que fez uma tese na área da Arqueometria, e não da Conservação e Restauro..

...Mas também se a Fundação para a Ciência e Tecnologia não financia projectos de investigação em Conservação, como é que se faz um doutoramento sem um projecto de investigação? Neste momento, a FCT não contempla como área a Conservação, e a área de Estudos Artísticos há 3 anos que está à espera de avaliação...por isso, assim, é muito complicado.

Mas isso deve-se a quê?

Não sei, não é dada qualquer informação...

Voltando ao nuclear, existe uma espécie de anátema contra o nuclear. Independentemente das opções que o nosso País possa vir a tomar acerca do futuro da energia nuclear, faz sentido não possuir uma forte competência nesse domínio?

Eu ainda continuo a pensar que é vantajoso que no nosso País existam técnicos especializados capazes de avaliar de forma competente tudo o que se relaciona com o problema da produção de energia nuclear e das questões que Ihe estão associadas. 0 antigo LFEN criouse para os preparar. Foi dissolvido quando ainda tinha pouca idade, foi incluído depois no LNETI e ressuscitado mais tarde sob o nome de ITN. Apesar disso, ainda lá ficaram técnicos muito competentes nesse domínio. Mas se no ITN nāo estiverem atentos à sua manutenção, lá se vão as competências... No que respeita às Universidades, acho que num certo sentido se abandonou tudo ou quase tudo o que se relacionava com o nuclear, mesmo questões importantes do ponto de vista da investigação, que passam pelo uso de espécies radioactivas e de métodos nucleares. Por exemplo, quando eu comecei a dar aulas de Radioquímica no Técnico, no ano lectivo de 1968/69, a disciplina era obrigatória e tinha a duração de dois semestres. Alguns anos depois passou a optativa, com a duração de um semestre. E julgo que, depois da minha jubilação em 1998, deixou de haver tal disciplina. Hoje, creio que ninguém a ensina em parte algurna do nosso País, nos cursos normais. Mas, mais grave ainda, raramente se criaram condições laboratoriais que permitam a manipulação dessas espécies com toda a segurança, o que é inacreditável. E ainda há gente no nosso País, fora do ITN, que faz uso de espécies radioactivas, como alguns bioquímicos..

...na medicina...

. sim alguns médicos têm mantido também interesse pelas espécies radioactivas. A radiofarmácia continua ainda muito viva, é uma área de investigação onde se faz muita coisa, e as aplicaçōes dos radiofármacos não diminuíram, antes pelo contrário. Usam-se cada vez mais em certos hospitais..

.. Mas, voltando à sua questão, julgo que será vantajoso manter competências. A verdade é que a via nuclear para a produção de energia é uma das vias importantes para o Homem. Em muitos países, a energia nuclear ainda está a ser produzida e, provavelmente, continuará a sê-lo por muitos anos. Consciente dos perigos que tal produção acarreta, penso que ela deve manter-se como hipótese a considerar no futuro e que deveríamos zelar pala manutenção das referidas competências.

Na sua opinião, deverá o objectivo do ensino Universitário em Química ser o de educar um elevado número de alunos com conhecimento superficial de Química ou poucos com conhecimento profundo do assunto?

Para o ensino Universitário em Química... não estou a pensar na formação de professores para o ensino secundário.. sou partidário dum ensino para um pequeno número de alunos feito em profundidade...

Acha que isso é compatível com os 3 anos que o documento de Bolonha sugere?

É capaz de ser muito difícil fazê-lo em 3 anos, sobretudo se quisermos introduzir-lhe uma forte componente experimental o que me parece essencial.

Até agora na sua carreira científica, o que mais lhe agradou e o que mais lhe desagradou fazer?

Dum modo geral, tenho o hábito de me apaixonar pelos problemas que vou deparando pelo caminho e de me entregar à sua resolução com grande entusiasmo. Deste modo, quase tudo o que tenho feito me tem dado satisfação. Se 
as coisas me parecem desinteressantes, não pego nelas. Sou incapaz praticamente de Ihes prestar atenção. Agora se Ihes descubro interesse, entrego-me a elas com paixão e isso dá-me prazer, diverte-me. Tenho às vezes dito a algumas pessoas... e é verdade... que tenho sido uma criatura feliz porque tenho levado a vida a fazer coisas de que gosto. $E$ quando elas começam a tornar-se feias, por qualquer motivo, prefiro libertar-me delas do que prosseguir com amargura.

Quer deixar algum conselho a um jovem Químico em início de carreira?

Que procure descobrir a beleza das questōes interessantes, propostas por alguém ou encontradas por ele. E uma vez isso conseguido, que procure abraçá-las e resolvê-las com entusiasmo, com a paixāo que normalmente se tem por tudo que é belo.

* Actual directora do Instituto Português de
Conservação e Restauro (IPCR)

\section{Perfil biográfico do Professor João Manuel Peixoto Cabral}

João Manuel Peixoto Cabral nasceu em Torre de Moncorvo, a 30 de Maio de 1928, completou a Licenciatura em Engenharia Química, pelo Instituto Superior Técnico, em 1952, obteve diplomas pela Isotope School, Harwell, em 1953, e pela Reactor School, Harwell, em 1956, doutorou-se em Ciências Básicas de Engenharia, pela Universidade Técnica de Lisboa, em 1968, e obteve a Agregação em Química Inorgânica e Analítica, pela mesma Universidade, em 1971.

Iniciou, em 1952, a sua actividade de investigação em química analítica usando técnicas radioquímicas, no Centro de Estudos de Química da Comissão de Estudos de Energia Nuclear, no Instituto Superior Técnico, sob a supervisão do Prof. A. Herculano de Carvalho.

Em 1960, ingressou no Laboratório de Física e Engenharia Nucleares (LFEN) da Junta de Energia Nuclear, em Sa- cavém, onde criou um Grupo de Radioquímica. Durante alguns anos, foi, também, membro do Gabinete de Estudos da empresa Amoníaco Português. Foi nomeado Director do Departamento de Química do LFEN em 1968, cargo que desempenhou até 1992, altura em que foi nomeado director do Instituto José de Figueiredo (1992-1993).

Começou a exercer funções docentes no Instituto Superior Técnico em 1968 , tendo sido contratado como professor catedrático convidado em 1976. Leccionou Química Geral, Métodos Instrumentais de Análise e Radioquímica.

Aposentou-se em Maio de 1998 com a categoria de investigador coordenador do quadro de pessoal do Instituto Tecnológico e Nuclear, funções que desempenhava desde 1979.

A sua principal actividade científica foi desenvolvida nos domínios da radioquímica, química analítica e química inorgânica. Quando a Junta de Energia Nuclear foi dissolvida, orientou as suas actividades para áreas de inter- secção entre as ciências físico-químicas e as ciências humanas. Dessa actividade resultou a criação de um laboratório de datação por radiocarbono e de um grupo de arqueometria.

É de realçar que foi o responsável pela implementação da área científica da Radioquímica no Laboratório de Sacavém e que foi o grande impulsionador da introdução, em Portugal, de uma abordagem da Arqueologia e da Arte utilizando metodologias da Química e da Física.

Publicou cerca de uma centena e meia de trabalhos científicos em revistas da especialidade, dos quais cerca de metade no domínio da arqueometria.

Continua a colaborar com investigadores do Instituto Tecnológico e Nuclear e iniciou recentemente uma colaboração com o Departamento de Conservação e Restauro da Universidade Nova de Lisboa.

António Pires de Matos; Jaime da Costa Oliveira
The public seems to be more and more dissatisfied by the fact that the substantial investments which are expended for science and education so far have not solved the problems of society. It almost seems that, with expanding technologies and consequential rise in the amount of "desirable" consumer goods, the gap between the "haves" and "have nots" steadily widens. This may be a contributing factor to the social unrest and the mindless crimes against property and human lives. Thus, a concerted effort by government, academia, and insdustry has to be initiated in the near future to find out how educational institutions in general and scholars in particular can contribute to the national welfare. It seems that the problems may be solved only when the next generation is educated in body, mind, and spirit, that is, beyond the factual knowledge of science. Specifically, the rising generation has to be taught to appre- ciate and especially respect the history of mankind and its cultures, including the arts, in their diversity and their important place in life. Moreover, we need to appreciate the beauty but also the vulnerability of Planet Earth, which requires our caring responsibility for life in all its varied forms for generations to come.

Rolf E. Hummel in "Understanding Materials Science", Springer-Verlag, 1998 


\section{Subscribe Now!}

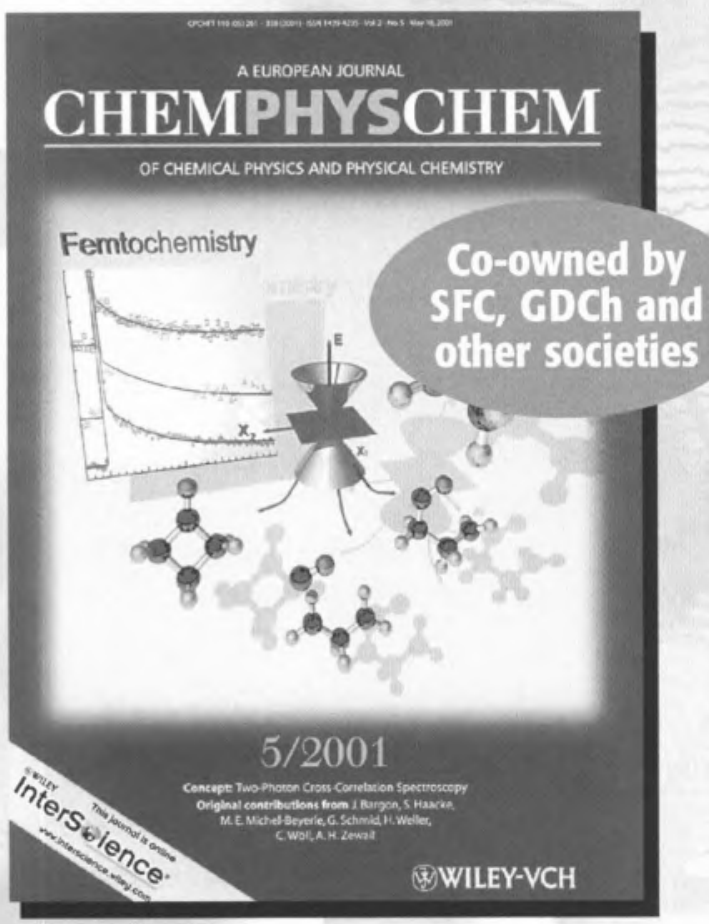

\section{ChemPhysChem}

A European Journal of Chemical Physics and Physical Chemistry

2002 Volume 3, 12 issues per year,

ISSN Print 1439-4235

ISSN Electronic 1439-7641

\section{ChemPhysChem - Where Chemistry Meets Physics Meets Chemistry...}

ChemPhysChem amalgamates the wide and flourishing field ranging - to name just a few topics -

- from atmospheric science to hard and soft condensed matter

- from femtochemistry to nanotechnology

- from complex biological systems to single molecule research

- from clusters and colloids to catalysis and surface science

- from electro- to photochemistry

\section{Papers from distinguished scientists worldwide, such as}
Z. I. Alferov
G. Ertl
C. A. Mirkin
C. Amatore
C. Friend
C. D. Bain
J. S. Kilby
C. N. R. Rao
V. Balzani
H. Kroemer
J.-M. Savéant
C. Bräuchle
R. Lavery
R. J. Saykally
E. A. Carter
J.-M. Lehn
G. Wegner
C. Zannoni
A. Corma
R. D. Levine
R. N. Zare
F. C. De Schryver
H. Matsuhara

Available as a separate journal and as a part of attractive packages with Angewandte Chemie (Int. Ed.) Please visit www.chemphyschem.com

\section{Virtual Sample Copy: FREE online access to full text of sample copy: www.interscience.wiley.com}

Please enter my/our 2002 subscription to ChemPhysChem
At the institutional rate*:

\begin{tabular}{|c|c|c|}
\hline print & & electronic \\
\hline$€ \quad 598,-$ & $\square$ & $\in \quad 598,-$ \\
\hline sFr 1028,- & $\square$ & sFr 1028,- \\
\hline US\$ 648,- & $\square$ & US\$ 648,- \\
\hline
\end{tabular}

\section{Please send me a free sample copy}

Please return this order form to your local bookseller or to:

Customers in Germany, Austria, and Switzerland:

WILEY-VCH Reader Service

P. O. Box 101161 ,

D-69451 Weinheim, Germany

Phone: $+49(0) 6201-606147$
Fax: $+49(0) 6201-606172$

e-mail: subservice@wiley-vch.de
At the personal member rate: print

$\square € 148$,- $\quad$ Europe

$\square$ sFr 248,- $\quad$ Switzerland

$\square$ US\$ 158,- $\quad$ All other countries
Please tick: $\square$ private $\square$ business
Customers in all other areas: John Wiley \& Sons, Ltd. Journals Administration Department I Oldlands Way

Bognor Regis West Sussex, PO22 9SA, UK Phone: +44 (0) 1243-779 777 Fax: +44 (0) 1243-843232 e-mail:cs-journals@wiley.co.uk 